\title{
A novel CuS/graphene-coated separator for suppressing the shuttle effect of Lithium/sulfur batteries
}

\author{
Yongguang Zhang ${ }^{1}$, Liancheng Sun ${ }^{1}$, Yan Zhao ${ }^{1}$ \\ ${ }^{1}$ School of Materials Science and Engineering, Research Institute for Energy Equipment Materials, \\ Hebei University of Technology
}

E-mail: yongguangzhang@hebut.edu.cn

We demonstrate a facile synthesis process to fabricate and deposit flower-like CuS/graphene nanocomposite on a multi-functional separator for efficient immobilization of polysulfides of lithium/sulfur (Li/S) batteries. Admirablely, as-prepared CuS/graphene composite endows enriched oxygen-functional groups and excellent electrical conductivity for cathode area. The introduction of $\mathrm{CuS} /$ graphene-coated separator effectively reduced the dissolution of lithium polysulfides as well as enhanced the integrity of the sulfur cathode for $\mathrm{Li} / \mathrm{S}$ batteries. The cell with this modified separator delivered an enviable discharge capacity of $1302 \mathrm{mAh} \mathrm{g}^{-1}$ at $0.2 \mathrm{C}$, as well as an excellent reversible capacity of $760 \mathrm{mAh} \mathrm{g}^{-1}$ after 100 cycles. Furthermore, an outstanding rate capability of $568 \mathrm{mAh} \mathrm{g}^{-}$ ${ }^{1}$ at 3.0 $\mathrm{C}$ has been achieved in the cell with $\mathrm{CuS} /$ graphene-coated separator. The results reveal that $\mathrm{CuS} /$ graphene-coated separator shows an admirable potentiality to boost the performance of nextgeneration $\mathrm{Li} / \mathrm{S}$ batteries.
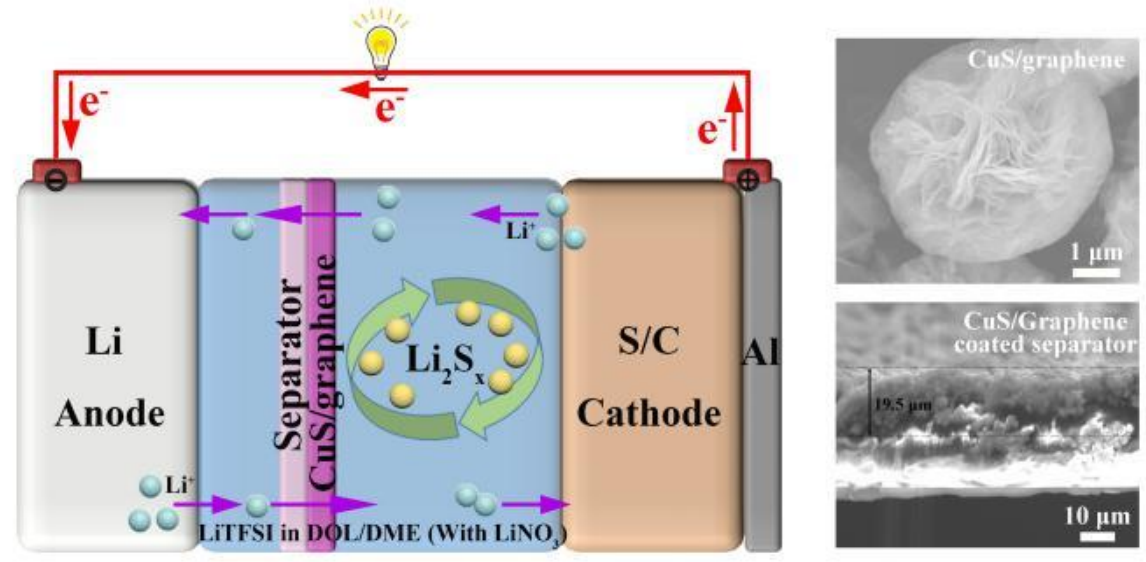

Fig.14 